\title{
English Grammar and Thai University Students: An Insurmountable Linguistic Battle?
}

\author{
Saksit Saengboon ${ }^{1}$ \\ ${ }^{1}$ School of Language and Communication, National Institute of Development Administration (NIDA), Bangkok, \\ Thailand \\ Correspondence: Saksit Saengboon, School of Language and Communication, National Institute of Development \\ Administration (NIDA), Bangkok, Thailand. E-mail: saksit2505@gmail.com
}

\author{
Received: September 9, 2017 Accepted: October 5, 2017 Online Published: October 9, 2017 \\ doi: 10.5539/elt.v10n11p22 URL: http://doi.org/10.5539/elt.v10n11p22
}

\begin{abstract}
This study aimed at investigating English grammar knowledge of a group of Thai university students. The three main research questions revolved around their knowledge of English grammar, the kinds of difficulties they had encountered in using the grammar as well as their perceptions of the roles of grammar in using English. The participants were administered two types of grammar test: one was the grammar production test (20 items), and the other was the grammar recognition test (40 items). The average scores of the tests were relatively low: $7.30 / 20$ and $21.13 / 40$, respectively. The interview results suggested that the participants viewed grammar as important in learning and using English effectively. They also reported that appropriate teaching of grammar was beneficial as long as the communicative use of the grammar was emphasized. Further, a thorough analysis of sentence structures, which was one of the foci of the lesson learned, helped them to gain a better understanding of English sentences, enabling them to read academic texts more effectively. In short, the participants believed that grammar was essential and was something that was not insurmountable albeit the low scores reported above.
\end{abstract}

Keywords: English grammar, instruction of English grammar, English language policy, communicating in English

\section{Introduction}

\subsection{Introduction to the Problem}

Conventional wisdom has it that communicative competence in a language is the ultimate goal of any language instruction programs. In order for the second language (L2) learner to develop communicative competence, he/she must have as a solid foundation grammatical competence. Indeed, grammar is a sine qua non of effective language use; without grammar the L2 learner cannot develop higher skills of language use such as writing and formal speech (Andrews, 2003; Borg, 1998; Borg \& Burns, 2008; Ellis, 2006; Graus \& Coppen, 2015). However, Thai students at all levels of education appear to be unable to communicate well in English. The problem of low English proficiency among Thai students is publicly known as reported through scores of such standardized tests as TOEFL, TOEIC and IELTS and local English tests such as the O-NET exam for college-bound students. The dismal knowledge of English is a serious concern among educators, prospective employers or even among students themselves. This concern over low English proficiency is compounded by the fact that laypersons, encountering the word grammar, are misled into believing that it is a hindrance to one's willingness to communicate in an L2, especially given real-life communicative situations where grammar seems to play almost no role in getting one's message across.

\subsection{Context of the Study}

As an institution of higher learning in the EFL context, the university under study is located in the suburbs of Bangkok whose main mission is to provide programs of study at the graduate level only. While the university focuses on graduate studies in social sciences, the majority of the students are considered having intermediate or lower-intermediate English proficiency. This appears to create some problems because the university is striving towards an international stature with the implication that English is used as a medium of instruction in many of its programs. In most cases, students in such programs tend to have a sufficiently good command of English. However, in this study, the researcher selected a particular program of study at the master's level, whose medium 
of instruction is Thai. In fact, the program was selected purposively because the students were required to study English intensively in order to prepare themselves in terms of English knowledge for the study at the master's program. As far as its structure is concerned, the program lasts one-and-a half year, attended by students with a bachelor's degree, ranging from sciences such as botany to the humanities such as English from a university accredited by Thailand's Office of Higher Education. Their goal of attending the course is to develop English language proficiency that would enable them to read academic texts and to use English generally. As previously mentioned, the L2 learner's communicative competence rests upon grammatical competence. Therefore, this study focuses on the ascertaining of English grammar knowledge of the participants. Findings to be reported may shed light on the nature of grammatical knowledge of the participants and ways to enhance their grammatical competence, an important stepping stone to fuller communicative competence. Given the focus of the study, the main research questions are the following:

1). How do the participants perform when using English grammar?

2). What difficulties do the participants have in using English grammar?

3). What are the participants' perceptions towards grammar and its role in English language instruction?

\section{Literature Review}

\subsection{English Education in Thailand: Opportunities and Challenges}

English has been a school subject in Thailand since 1921 (Baker, 2008). In this respect, virtually all Thai students at all levels of education learn English as a foreign language (EFL), meaning that most Thai students do not have as much exposure to good quality English as do English as a second language (ESL) students who tend to use English on a daily basis. Perhaps this is a real cause of low English proficiency among Thai students. Meagre language input, coupled with a dearth of real opportunities to use English for many Thais, suggests that their knowledge of the linguistic system of English e.g. grammar knowledge - both recognition and, especially, production skills - might be questionable, especially given the fact that Thai students' English scores of standardized tests such as TOEFL, TOEIC and IELTS are relatively low compared to other nationalities.

Although English has never been a compulsory subject, it is the most selected subject of all the foreign languages on offer, namely, French, German, Japanese, and more recently Spanish as well as Korean. In fact, English is taught from grades 1 to 12 plus a year or two in college, so it is often taunted that most Thai students spend almost 13 years or so studying English only to realize that they are not communicatively competent in real situations. This deplorable state of English proficiency has been much criticized to the point that the Thai government, especially the Ministry of Education, has found this dire consequence intolerable and that drastic measures should be implemented before it is too late. Among the measures taken so far have been revamped curricula and the so-called practical training for local teachers to learn new tricks of the trade. The revamped curricula emphasize the communicative nature of language instruction, and depending on how the term "communicative" is defined, a given curriculum could end up ruling out grammar from the courses. According to Canagarajah (2012), "[t]his top-down imposition of TESOL methods without a consideration of local pedagogical traditions has led to dysfunctional classroom conditions in my parts of the world" (p. 265). Here, Canagarajah was lamenting the inclusion of communicative language teaching, a Western-conceived teaching approach, in haste. One ramification of this import of communicative language teaching is that grammar, especially explicit grammar instruction, has fallen in disfavor among publishers and teachers. As can be anticipated, no inclusion of explicit grammar instruction may, in turn, result in even lower proficiency because the students, studying English in an EFL environment, do not seem to have a good grasp of language elements that in fact could assist them in developing communicative competence.

The less emphasis on grammar teaching in Thai educational settings is an obvious example of what Canagarajah (2016) dubbed as "The Paradigm Wars" (p. 11). On the one hand, those favoring a study of language as a manifestation of communication would consider grammar alone insufficient, reflecting the following sentiment that "[w]hen no languages or values are shared by interlocutors, grammar alone cannot help us account for communicative success" (pp. 14-15). On the other hand, those following in Chomsky's footsteps argue that "...grammar is key to knowing a language; that this knowledge is located in and developed through one's innate cognition..." (p. 11). Although influential in some ways, this latter position has waned in comparison to the former. This is because the very notion of grammar has been depicted as a static system unable to accommodate real communicative use of language. Given the focus of this paper, the paradigm wars concerning language are beyond the scope of the paper. The term English grammar as used in this study refers to grammar as basic and necessary linguistic elements such as rules involving the subject-verb agreement, parts of speech and so on. Although I realize that the nature of language learning and teaching is multifaceted, making grammar a mere 
linguistic semiotic resource (The Douglas Fir Group, p. 25), it is worthwhile to investigate the level of knowledge and use of English grammar because it is the very basic building blocks for a more complete (hence successful) use of language. Language use as much as language learning entails appropriately developing communicative competence. Communicative competence, originated by Hymes (1972 as cited in Richards and Rodgers, 2001) argues for the awareness and cultivation of "...what a speaker needs to know in order to be communicatively competent in a speech community" (p. 159). Although Hymes proposed this view to characterize first language acquisition and performance, L2 researchers borrowed the concept to account for the ultimate goal of L2 acquisition/learning. For example, Canale and Swain (1983) explains that communicative competence in L2 acquisition/learning encompasses the following dimensions: grammatical competence, sociolinguistic competence, discourse competence and strategic competence. They elaborated on grammatical competence as knowledge of grammar broadly defined. An example of grammatical competence is the ability to understand and use parts of speech correctly. However, grammar knowledge per se cannot assist a person to successfully use a language; that person must necessarily have the other competencies as well.

Although more recently, World Englishes or global Englishes has become increasingly important, implying that local contexts of English usage are more important than the traditional concept of "standard" English, the researcher argues that grammar still remains relevant. For World Englishes or global Englishes does not mean "wrong" English.

\subsection{Defining Grammar}

Grammar is a system of sounds, words, sentence and meaning of a language. There are several kinds of grammar. First, prescriptive grammar refers to grammar rules stated in a grammar book. It is rules of language determining what is right and what is wrong. That is, it is about "the way that a language "ought to" be used" (Celce-Murcia at al., 2014). Second, descriptive grammar refers to grammar as used in real life situations. According to Celce-Murcia et al. descriptive grammar is "... a description of how speakers of a language actually use the language, even when it does not conform to what prescriptive grammars prescribe and proscribe" (p. 257). This type of grammar is sometimes referred to as discourse grammar, although the latter places an emphasis on language beyond the sentence level. Third, pedagogical grammar refers to grammar rules or points that are selected to be a focus of instruction. For example, grammar is taught based on the pre-determined purpose of learning rather than teaching grammar based on grammar rules without any authentic goals of usage.

For the purpose of this study, which is to learn about grammar knowledge, the researcher will refer the notion of grammar to descriptive or discourse grammar except pedagogical grammar. This is because the purpose of the study is to find out about both grammar recognition and grammar production. In addition, grammatical competence is of great importance in building up one's communicative competence, a topic to be discussed below.

\subsection{Focus on Form vs. Focus on FormS}

According to Doughty and Williams (1989), traditionally English grammar instruction focuses on grammar forms in isolation (Focus on FormS), reflecting the long-held belief that learning English as a second or foreign language is to learn its grammatical system. This belief held sway for a number of years until the communicative approach movement took its place some 30 years ago or so. Focus on FormS is a lynchpin of traditional language teaching such as the grammar-translation method and Audio-lingualism. In the Focus on FormS classroom, time is devoted to dissecting grammar explicitly, so that the L2 learner comes to appreciate how English grammar works. A focus on meaningful communication is not prioritized. However, with the advent of communicative language teaching (CLT) (Celce-Murcia, Brinton and Ann Snow, 2014), a new trend was proposed that grammar should be taught in context, reflecting the belief that language is for communication. That is, grammaris never to stand alone. It has to be accompanied by its use in real life situations.

Many realizations of communicative language teaching such as task-based language teaching (TBLT), cooperative language teaching, and content-based language teaching are premised upon the notion of Focus on Form. It is believed that Focus on Form enables the L2 learner to see the interconnectedness of forms, functions and meanings of English grammar in a given situational use. Moreover, CLT being an approach as it is, does not preclude the role of grammar in acquiring/learning an L2 but rather grammar should be incorporated into the English class with some degree of flexibility relative to "... the contextual design and procedure of the classroom" (Ariatna, 2016). That said, it could be argued that grammar deserves a place in teaching and learning acts. As Atkinson (2017) put it, "...teaching is not simple or uniform, but rather complex and multidimensional: multiple types of activity that provide multiple types of learning opportunities" (p. 14). In the same vein, grammar teaching should be cast in this light, providing ample learning opportunities for the learner to come to 
terms with English grammar, a linguistic component they find it hard, if not impossible, to avoid.

\section{Research Design}

\subsection{Participants}

Participants consisted of an intact group of Thai graduate students $(n=30)$ who enrolled in a master's degree program at a Thai university in Bangkok. These students graduated with a bachelor's degree in various fields of study e.g., political science, management, engineering, nursing science and so on. Their common characteristic as far as English proficiency is concerned is their English ability was at the lower-intermediate level (presumably comparable to $\mathrm{B} 2$ level in CEFR).

\subsection{Data Collection Techniques}

A two-pronged approach to data collection was employed. First, the participants were administered a paper-and-pencil test (60 items), comprising two main sections: one was a gap-filling task (20 items) and the other was the TOEFL paper-based test in which they were to fill in incomplete sentences and to identify correct answers relative to grammar points being tested such as subject-verb agreement, the use of pronoun, articles, adjective, adverb and so on (Appendix A). Basically, the first section of the grammar test was intended for grammar production; the second, grammar recognition. Second, based on their performances of the grammar tests, they were interviewed through email, focusing on their opinions about their own English proficiency and English education in Thailand generally (Appendix B)

As for the reliability and validity, the gap-filling task as mentioned above was rated for its appropriateness by two experts in applied linguistics. They were, for the most part, in agreement as to the suitability of the task. The second test, which was the TOEFL paper-based test items, was derived from a publicized version of the real TOEFL test administered by ETS. The interview questions employed were considered by the same two experts in applied linguistics for their suitability following the semi-structured format.

\subsection{Data Analysis}

Results of the participants' performances in the first task were analyzed focusing on grammar rules involving each of the 60 -items being tested. This was followed by an analysis of errors/mistakes they had made in the essay task with a view to determining whether there were any discrepancies in terms of recognition and production tasks. To triangulate (Merriam \& Tisdell, 2016) the results, the third task, an email interview, enabled the researcher to better understand their their opinions regarding the roles of English grammar in English education generally.

\section{Findings and Discussion}

\subsection{The Grammar Tests}

The overall performance of the participants' on the grammar production test (20 items) was somewhat poor with a mean score of 7.30/20, a maximum score of 11 and a minimum score of 0 . As for the grammar recognition test, the average score was $21.13 / 40$, with a maximum score of 34 and a minimum score of 6 . Unsurprisingly, the participants' performance of the grammar recognition test was relatively higher than that of the grammar production test. However, the mean scores of both tests suggested that the majority of the participants did not have a solid knowledge of grammar. As could be expected, the grammar production test turned out to be somewhat difficult for the participants. In some of the items, none could get the right answers. Also, various elements in those sentences could make it even harder for some participants to come up with the correct answers. For example, item 13 requires a past participial form of the verb "go," which when placed in the sentence initial position was difficult because of its marked structure. (See Appendix A). The ensuing report of findings and discussion will focus on those grammar points that appeared to be the ones the participants answered incorrectly. 
Table 1

\begin{tabular}{ll}
\hline Item & Types of Grammar \\
\hline 1 & Subject-verb agreement \\
2 & Adjective \\
3 & Noun \\
4 & Verbal (perfect participial phrase) \\
5 & Relative pronoun \\
6 & Phrasal verb \\
7 & Adverb \\
8 & Conjunction \\
9 & Pronoun \\
10 & Verbal (past participial phrase) \\
11 & Preposition \\
12 & There + verb to be \\
13 & Inversion (past participial verb) \\
14 & Verbal (present participial phrase) \\
15 & Subject-verb agreement \\
16 & Noun (plural form) \\
17 & Noun clause marker \\
18 & Adverb clause marker \\
19 & Comparative form \\
20 & Verbal (past participial phrase) \\
\hline
\end{tabular}

Of the grammar points tested, a closer analysis revealed that the participants found the "subject-verb" agreement category (item 1) least difficult with 17 of them answering correctly. However, the adjective modifying a noun category (item 2) was found to be very difficult with 16 of them getting it wrong. This is because the slot to be filled "Many ___ students..." is preceded by a quantifier "many" and Thai students in general seem to be used to the following pattern, "many of...," thereby resulting in 16 of them putting the word "of" in the slot, whereas if they had written down any adjective that could modify the word "students," they would have received a point. This finding suggests that many of the participants did not truly understand the use of "many." Rather, they relied on their rote memorization of the structure "many of..." My interpretation is that the structure itself is not opaque but the problem lies in the participants' misunderstanding that 'many' has to always be followed by "of".

Another salient finding that suggests that the participants did not have the right understanding of the structure involved is that of "inversions". In item 13, [Gone are the days when the farmer milked one cow at a time. Today most dairy farms use machinery], the participants were supposed to write down the word "Gone" in the slot, but none of them gave the right answer. Instead, five of them answered "There", whereas the remaining gave many kinds of wrong answers such as "in the past". The reason why the word "There" was given may have been because those participants memorized this basic sentence pattern, "there +is/are" Again, the participants did not understand the inversion structure, nor did they rely on the context for the right answer.

When item 13 above is compared to item 12, [In the internal combustion engine found in most cars, there are four, six, or eight cylinders], it turned out that 11 participants could provide the right answer, "there are". The higher number of correct answers for this item suggests that the structure of item 12 is less marked than that of item 13, confirming the long-held understanding in second language acquisition that unmarked structure is more understandable and thus easier to process and produce than the marked one. The ease with which the participants had in answering the unmarked structure is also evidenced in their responses to item 15 [A diary $\underline{i s a n}$ informal daily written record of the events in someone's life]. Twenty-six participants answered correctly. The same holds true for item 18 [People love flowers because they are colorful and they smell good], and item 19 [Long ago there were more large forests in the world than there are today]. In both items, twenty-seven participants 
answered correctly. In fact, the answers "because" and "than," being function rather than content words, lent themselves easily for correct answers. Also, this confirms the point made earlier that unmarked structures are acquired before marked ones.

As for item 14 [Some historians believe that cotton was first used in Egypt around 12,000 BC. Pieces of fabric containing a mixture of cotton and fur have been found in Mexico], none of the participants answered correctly. The present participial structure of the answer, coupled with the fact that the slot needed a content word, made this structure marked and therefore very difficult for this group of participants.

Another item worth considering is item 17, which deals with a noun clause marker "what". [Scientists learn much of what they know through controlled experiments]. Only two participants provided the correct answer. Instead, 11 participants wrote down the word 'how' for an answer. This implies that the participants did not know that the word "know" requires a direct object, making "what" obligatory. This kind of global error (e.g. error that is induced by the whole sentence structure) is also evidenced in some of the other items. For example, for item 5 [I got some bad news today. The store where I work is laying off staff], twenty-five participants got the right answer. In this case, most answers were correct because the adjectival clause marker "where," which indicates a place, is more salient and less marked than the noun clause marker "what". This finding provides evidence that clause markers differ in terms of difficulty, depending on the global structure involved.

In sum, most participants had difficulty producing correct answers to many questions in both the grammar recognition and production tasks. The mistakes made varied in severity depending on the structures involved. Those marked structures posed a greater challenge than the unmarked ones.

The following section discusses the participants' $(n=18)$ response patterns to interview questions covering the overall English teaching situations in Thailand and, more specifically, their ideas about explicit grammar instruction they had been taught at their current university.

\subsection{The Participants' Responses to the Interviews}

The majority of the participants considered grammar instruction important and relevant. In fact, they seemed to welcome grammar learning as long as such learning was handled with care. The participants also went on to explain in greater details their preferences concerning grammar teaching as follows.

\subsubsection{Rote-learning of Grammar vs. Grammar for Real Use}

The participants all agreed that grammar had a role to play in English language learning. In fact, they pointed out that grammar was necessary, although how it should be taught was another matter. The necessity of grammar teaching was one thing; how it should be taught was quite another. For example, P 02 put it that, "English teaching in Thailand is taught to the examinations, not to the real use. That's the problem. The grammar of English is not taught properly that is in line with how it is actually used." In this regard, P03 lamented that "my Thai English teachers asked us to simply memorize grammar rules without an emphasis on how they are used. That's deplorable. Rote-memorization of grammar rules are useless, because students cannot use them in real-life situations" P04 pointed out that "teaching grammar is fine, but it should be done in conjunction with the other language skills." P05 mentioned more or less the same point. P06 further argued that "more emphasis should be placed on how grammar is actually used in many daily situations; grammar for exams should not be prioritized." All these examples are well resonated in the voices of the other research participants, although P12 raised an interesting point that "English is for communication, not for a display of perfect grammar. There's no need for perfect grammar in conversational English except for certain tasks where grammatical accuracy is inevitable." It is interesting to note that P14 explicitly stated that "an emphasis on grammar is good. I really enjoy learning how different grammar rules are used in email communication."

In short, the participants were all aware that grammar was significant for effective communication. They, however, cautioned that grammar should be taught appropriately. Most of their concerns revolved around their own undesirable experiences of having been taught grammar uncommunicatively. They found the examination-oriented culture of the Thai educational system ineffective, resulting in poor performance of many Thais when communicating in English. All clamored for "grammar in use."

Given the participants' views on the role of grammar discussed earlier, it may be concluded that the participants believed that the teaching of English should give them not only "...opportunities for meaning-focused communication and using language for communicative purposes, [but they also] need opportunities for noticing and attention to form" (Nassaji, 2015, p. 1). 


\subsubsection{Multi-dimensional English Language Policy: It Takes the Whole Village to Raise a Child}

As regards the English language policy, most of the participants emphasized the importance of having a language policy that enables school administrators, teachers, parents and students to take responsibility in making the learning of English a success. One of the participants, P05 elaborated on this below:

The policy should instill in all stakeholders, be they teachers, students, parents and society at large, a new value of the English language in today's world, one that helps them eliminate unfound and unreasonable dread of the language. Making mistakes is part of the deal. Besides, they should bear in mind that a vast body of knowledge out there is rooted in English. Further, English teachers at all levels must keep developing their English language skills because they will become role models. If possible, schools across the country should be provided with at least one English native speaker as a resource person. As far as learning assessment is concerned, students' language development should be gauged holistically. In addition, a center should be set up to provide a free platform for students to practice their English. If all these ideas are implemented, I'm sure English education in our country will get better.

The comments above speak volumes of the dire situations English language teaching in Thailand has been in. Reports of poor English proficiency among Thais abound. The mass media deplore it. While the other participants concurred with P05's ideas of how English language policy should focus on, some even went further emphasizing the importance of Thai English teachers. P06, in comparing the teacher to a mold, said that "the teacher should be trained properly so that they will have a sound knowledge of English and deep insights into how to teach professionally." P08 sounded somewhat extreme, suggesting that "English should be made another official language, thus providing a truly international ambience at school." In keeping with the international spirit, P09 proposed that the IPA system should be taught to students, so that they will speak with a proper accent when communicating in English."

In sum, the participants believed that English language policy could make it happen that Thais communicate better in English. A viable policy should be multi-dimensional. It should encourage all parties concerned to take English seriously. As much as the students will need to apply themselves harder, teachers must see to it that their English knowledge (know-what) as well as their teaching activities (know-how) are appropriate for the task at hand. The ideas proposed here resonate well with the concept of "teaching English through English," most recently proposed by Richards $(2017$, p. 7$)$. The overwhelming majority of the participants strong advocated a widespread use of English in Thai schools.

\subsubsection{Sentence Analysis: A Way Forward}

When asked whether they found their learning English in the Reading Skills Development for Graduate Studies class, they realized that doing sentence analysis was useful. Although the course contents covered other reading skills such as sentence comprehension, sentence interpretation, paragraph and multi-paragraph reading, and journal article reading, the focus on sentence analysis was the part that dealt directly with grammar. So it was included in this study. The participants thought that doing sentence analysis provided them with a solid stepping stone toward the next level of language learning. All participants agreed that analyzing sentences into simple, compound, complex and compound-complex structures helped them to read systematically. For example, P01 said "I could parse units of grammar, which helped me to see clearly the relationships of sentence elements." P02 put it that, "sentence analysis helped me feel confident when translating academic English into Thai." P03 said, "doing sentence analysis enabled me to read with a deeper understanding, indeed." In order to avoid repetition here, the answers of the rest of the participants more or less reflected the practicality of doing sentence analysis. When seen in the light of second language acquisition (SLA) theories, asking students to do sentence analysis of authentic English sentences drawn from academic texts supports an argument in SLA that "language development is seen as a process of frequency tallies performed unconsciously by the brain. Each time an item is in the input, the brain tallies it, connects it, strengthens connections to it and with it, creates associations and networks of associations that eventually become a complex language system" (Malovrh \& Lee, 2013, p. 82). In the class, the participants had to many grammar exercises focusing on types of sentence mentioned above. The noticing and consciousness required in doing the exercises reinforced the participants' incremental understanding of the structures involved. Therefore, it is not whether grammar should be taught, but it is how grammar is taught that counts.

To answer the three research questions, the data analysis above suggests that most of the participants did not perform well in using English grammar, especially given the scores earned on the grammar production section, although the scores of the grammar recognition appeared better on average. The grammatical mistakes made by the participants varied in their severity. Those structures that are marked tended to display a high frequency of 
errors than unmarked structures. As previously stated, the overall performances of the whole group left a lot to be desired. The poor performance aside, the participants managed to provide many thought-provoking remarks concerning the roles of grammar and the way in which English should be taught in Thai schools. Their responses indicated that grammar was not an insurmountable battle for many of them. The war metaphor used in the title of this study seemed somewhat overblown.

As for RQ 2, the participants had difficulties in using many grammar points correctly, particularly the noun clause markers. Again, those difficulties, in their opinions, stemmed from the fact that they were not taught English grammar properly, that there was no need for them to use English daily, either at work or at home. It is only natural that certain linguistic features are more difficult to acquire than others. That is one of the reasons why the participants performed better on some items than the others.

In terms of RQ 3, the participants' strong support of grammar instruction concurs with what second language acquisition theories have to say. That is, “.... a high degree of accuracy in the L2 may be possible only if the learner also focuses her attention on forms" (de Bot et al., 2005, p. 76). In this regard, the participants further elaborated that they would prefer grammar teaching that helped them see the interconnectedness of sentence elements, to see the woods as well as the trees. According to SLA theories, "... explicit teaching approaches did more than ask students to use the language; they asked them to think metalinguistically—thinking about the language and discussing it like any other object of study." (Brown \& Larson-Hall, 2012, pp. 87-88). The findings as discussed so far suggest that dichotomizing such issues as teaching or not teaching grammar is irrelevant. The studies reviewed that touched on the notions of focus on form and focus on forms provide support to the participant's opinions that when it came to the two strategies, it was a matter of judiciously selecting which of the two strategies should be used for which linguistic features.

\section{Conclusion}

In this study, the researcher investigated knowledge of English grammar of a group of Thai university students. Grammar has always been a contentious issue among theorists and practitioners alike, especially in the Thai education system where myths have been floating around that the teaching of grammar inhibits Thai learners of English from communicating effectively. As would be anticipated, the participants performed poorly in the two grammar tests administered, although they found grammar relevant and important. Of the grammar points tested, certain items were found to be more challenging than others, especially in the grammar production test. The participants had considerable difficulties in using, for example, an inversion structure (item 13), whereas they did very well in answering a subject-verb agreement question (item 15). Notwithstanding their mediocre performances on the tests, the participants believed that grammar teaching, in particular the one they had received in the course they had enrolled in, was very useful. The explicit grammar teaching they had been exposed to as well as the meaningful practices that ensued and that focused on metalinguistic knowledge turned out to be beneficial. Lastly, the participants expressed their opinions regarding the English language policy that should be revamped to help Thais in general to feel more confident and have more opportunities to use the language in daily life. Whether this anticipated policy will materialize is everybody's guess but, for certain, the participants found grammar not an insurmountable battle.

\section{Limitations}

Results reported in this study cannot be generalized to other groups of Thai students because the participants constituted an intact group. In addition, the grammar tests, production and recognition skills, were paper-and-pencil tests, meaning they may not have measured the true proficiency level of the participants. Also, because the tests were given without any rewards either in terms of marks or other kinds of rewards, some of the participant may not have paid sufficient attention to them, potentially skewing the results obtained. The majority of the participants graduated with a bachelor's degree in social sciences in general; none majored in English. This might have explained why the overall scores in both tests were relatively low.

\section{Implications}

The findings as reported above shed light on implications for both teaching and research. In fact, the participants seemed to have a love-hate relationship with grammar. Below is a discussion of pedagogical and research implications.

\subsection{Pedagogical Implications}

Based on the participants' responses, it is obvious that grammar must be incorporated into the teaching of English. None of the participants objected to it. However, grammar has to be taught in ways that enable them to communicate effectively in English. That is, descriptive or discourse grammar, rather than prescriptive grammar 
should be stressed. In discourse grammar, forms, meanings and functions of a given linguistic feature are provided in context, making such a feature relevant for communication. The problem with traditional grammar teaching is that grammar is taught in isolation, following the prescribed curricula. This no longer works, in the eyes of the participants.

\subsection{Implications for Further Research}

Assigning students to write an essay (rather than to fill in the slots) might provide more in-depth information about the role of grammar in using English. This will ascertain their true proficiency level. Essay writing forces them to use their knowledge of English, which can reveal any other problem that they might have, such as word choices or idiomatic expressions. Also, participants might be invited from a more diverse group of students, so that generalization might be made that would more accurately reveal the English education scenarios in Thailand.

\section{References}

Atkinson, D. (2017). Homo Pedagogicus: The evolutionary nature of second language teaching. Language Teaching, 1-17. https://doi.org/10.1017/S0261444816000458

Andrew, S. (2003). Just like instant noodles: L2 teachers and their beliefs about grammar pedagogy. Teachers and Teaching, 9, 251-376. https://doi.org/10.1080/1354060032000097253

Ariatna. (2016). The need for maintaining CLT in Indonesia. TESOL Journal, 7(4), 800-822. https://doi.org/10.1002/tesj.246

Baker, W. (2008). A critical examination of English in Thailand: The role of cultural awareness. RELC Journal, 39(1), 131-146. https://doi.org/10.1177/0033688208091144

Borg, S. (1998). Teachers' pedagogical systems and grammar teaching: A qualitative study. TESOL Quarterly, 32, 9-38. https://doi.org/10.2307/3587900

Borg, S., \& Burns, A. (2008). Integrating grammar in adult TESL Classrooms. Applied Linguistics, 29, 456-482. https://doi.org/10.1093/applin/amn020

Canagarajah, S. (2012). Teacher development in a global profession: An autoethnography. TESOL Quarterly, 46(2), 258-279. https://doi.org/10.1002/tesq.18

Canagarajah, S. (2016). TESOL as a professional community: A half-century of pedagogy, research, and theory. TESOL Quarterly, 50(1), 7-41. https://doi.org/10.1002/tesq.275

Canale, J., \& Swain, M. (1983). From communicative competence to communicative language pedagogy. In J. C. Richards, \& R. W. Schmidt (Eds.), Language and Communication. London: Longman.

Celce-Murcia, M., Brinton, D., \& Ann Snow, M. (2014). Teaching English as a Second or Foreign Language (4th edition). UK: Heinle Cengage Learning.

de Bot, K., Lowie, W., \& Verspoor, M. (2005). Second language acquisition: An advanced resource book. New York: Routledge. https://doi.org/10.4324/9780203446416

Doughty, C., \& Williams, J. (1998). Issues and terminology. In C. Doughty, \& J. Williams (Eds.), Focus on form in classroom second language acquisition (pp. 1-11). Cambridge: Cambridge University Press.

Eckstein, G., \& Ferris, D. (2017). Comparing L1 and L2 texts and writers in first-year composition. TESOL Quarterly. https://doi.org/10.1002/tesq.376

Ellis, R. (2006a). Current issues in the teaching of grammar: An SLA perspective. TESOL Quarterly, 40, 83-107. https://doi.org/10.2307/40264512

Graus, J., \& Coppen, P. (2015). Defining Grammatical difficulty: A student teacher perspective. Language Awareness, 24, 101-122. https://doi.org/10.1080/09658416.2014.994639

Malovrh, P., \& Lee, J. (2013). The development dimension in instructed second language training. London: Bloomsbury.

Merriam, S., \& Tisdell, E. (2016). Qualitative Research: A Guide to Design and Implementation. New York: Jossey-Bass.

Nassaji, H. (2015). The interactional feedback dimension in instructed second language learning: Linking theory, research, and practice. London: Bloomsbury.

Richards, J. (2017). Teaching English through English: Proficiency, pedagogy and performance. RELC Journal, 
48(1), 7-30. https://doi.org/10.1177/0033688217690059

Richards, J., \& Rodgers, T. (2001). Approaches and methods in language teaching. Cambridge: Cambridge University Press. https://doi.org/10.1017/CBO9780511667305

The Douglas Fir Group. (2016). A transdisciplinary framework for SLA in a multilingual world. Modern Language Journal, 100(Supplement 2016), 19-47. https://doi.org/10.1111/modl.12301

\section{Appendix A}

\section{Part I: Grammar Production}

Directions: Read the following sentences and fill in each blank with the best word or phrase.

1. That Thailand is a country in Southeast Asia true.

2. Many students are worried about their grades.

3. The supermarket down the street is selling everything half price because they are going out of

4. The stuff the nurse gave me seems to , but it is making me awfully drowsy.

5. I got some bad news today. The store I work is laying off staff.

6. I'm soaked! It started to pour the minute I off the bus.

7. Do you know who took this message for Donald? I can read it.

8. The telephone rang several times while I was home this morning, I couldn't get to it.

9. Bangkok is home to two giant tunnels that drain floodwater into the city's main river: one is near Bung Makkasan and the is beneath Rama IX Road.

10. People have been mobilized to build defenses and drain land as heavy rains continue to fall.

11. In order for an airplane to fly, it must overcome the force of gravity and also move forward the air.

12. In the internal combustion engine found in most cars, four, six or eight cylinders.

13 . are the days when the farmer milked one cow at a time. Today, most dairy farms use machinery.

14. Some historians believe that cotton was first used in Egypt around 12,000 BC. Pieces of fabric a mixture of cotton and fur have been found in Mexico.

15. A diary an informal daily written record of the events in someone's life.

16. Scientists believe that animals experience such as happiness and sadness just like humans do.

17. Scientists learn much of they know through controlled experiments.

18. People love flowers they are colorful and they smell good.

19. Long ago there were more large forests in the world there are today.

20. The Internet allows information to be around the world. The World Wide Web allows users to access servers anywhere.

\section{Part II: Grammar Recognition}

1. Directions: Choose A, B, C or D that best completes each of the sentences below.

1. Andy Warhol was in the PoP Art movement who was known for his multi-image silk-screen paintings.
A. that one of a leading figure
B. a leading figure
C. lading figures
D. who lead figures

2. Even with vast research, there is still a great deal that is known about the workings of the human brain.
A. neither
B. none
C. no
D. not 
3. the United States consists of many different immigrant groups, many sociologists believe there is a distinct national character.
A. In spite of
B. Despite
C. Even though
D. Whether

4. Typically, in meadows or damp woods and bloom in the spring.
A. wild violets grow
B. wild violets growth
C. growing wild violets
D. the growth of wild violets

5. The art works of Madlyn-Ann Woolwich are characterized by strong, dark colors and fine attention to patterns of light the viewer's eye.
A. that attract
B. when attracted
C. which attraction
D. attract to

6. A grass-eating, river-dwelling mammal, the hippopotamus to the pig.
A. being related
B. is related
C. relate
D. relating

7. Woodrow Wilson 1912. as governor of New Jersey before he was elected President of the United States in
A. to have served
B. who has served
C. serving
D. served

8. ___ fish in Great Salt Lake, but its waters do contain small brine shrimp.
A. Why no
B. No
C. Not only
D. There are no

9. An etude is a short musical composition written especially a particular technique.
A. enable students practicing
B. enables students practicing
C. enable students to practice
D. to enable students to practice

10. Seldom games been of practical use in playing real games.
A. theories of mathematics
B. theorized as mathematics
C. has the mathematical theory of 
D. the mathematical theory has

11. The city of Kalamazoo, Michigan, derives its name from a Native American word "bubbling springs."
A. meant
B. meaning
C. that it meant
D. whose meaning

12. Jet propulsion involves of air and fuel, which forms a powerful exhaust.
A. a mixture is ignited
B. to ignite a mixture
C. a mixture of igniting
D. the ignition of a mixture

13. Salt is manufactured in quantities that exceed those of most, , other commercial chemicals.
A. of all not
B. not if all are
C. are not all
D. if not all

14. The United States consists of fifty states, has its own government.
A. each of which
B. each they
C. they each
D. each of

15. Though smaller than our solar system, quasar, which looks like an ordinary star, emits more light galaxy.
A. than an entire
B. entirely as
C. that the entire
D. entirely than

2. Directions: Identify the one underlined part, A, B, C, or D that must be changed for the sentence to be correct.

16. People usually wear clothing why two basic purposes - warmth and decoration.
A
B
$\mathrm{C}$
$\mathrm{D}$

17. In 1890 Kate Hurd-Mead became medical director of the Bryn Mawr School for girls, one

A

B

of a first schools in the United States to initiate a preventive health program.

$\mathrm{C}$

$\mathrm{D}$

18. Superior to all others woods for shipbuilding, teak is also used for furniture, flooring, and
A
B
$\mathrm{C}$
D

general construction.

19. Weather is the transitory expression of climate that can change great from day to day or
A
B
C
D

season to season.

20. Archeological investigations indicate that control of fire is an extremely old technical

A

B

attainment, though the time, place, and mode of his origin may never be learned. 


\section{C}

$\mathrm{D}$

21. Paul Revere designing the metal plates on which the first paper money in the United
A
B
$\mathrm{C}$
$\mathrm{D}$

States was printed.

22. It was after shortly microscopes were introduced at the beginning of the seventeenth
A
B
$\mathrm{C}$

century that microorganisms were actually sighted.

$\mathrm{D}$

23. Until the 1840 s, practically the only pioneers who had ventured to the western United A B

$\mathrm{C}$

States were trappers and a little explorers.

$\mathrm{D}$

24. Medical research indicates butlarge amounts of histamines can be responsible for colds,
A
$\mathrm{B}$
$\mathrm{C}$
$\mathrm{D}$

hay fever, and other respiratory reactions.

25. Yttrium is a silvery, metallic element used in the made of red phosphors for television
A
$\mathrm{B}$
$\mathrm{C}$
D

picture tubes.

26. Tropical forests exist close the equator, where both high temperatures and abundant
A
B
C
D

rainfall occur year-round.

27. The ease with which houseplants can grown causes them to be popular among amateur
A
B
$\mathrm{C}$
D

horticulturists.

28. Paintings of a religious, ceremonial, or history character tend to elevate their subjects
A
B
$\mathrm{C}$

above the level of ordinary existence.

$\mathrm{D}$

29. According to classical musical tradition, the term "sonata" is given to those works are A $\mathrm{B}$

written for solo piano or for a solo wind or stringed instrument.

$\mathrm{D}$

30. Precisely because photographs are produced by mechanical devices, a camera's images

$$
\text { A }
$$

B

now seem to some artists the perfect means for expression the modern era.

$$
\mathrm{C}
$$

$\mathrm{D}$

31. The discovery of the magnetic effects of coils made possible to measure an electric
A
$\mathrm{B}$
$\mathrm{C}$

current. 
32. Since the 1950s the city of Baltimore has financed several major programs of urban

A

B

renew, including rebuilding the Inner Harbor.

$\mathrm{C}$

$\mathrm{D}$

33. For at least 4,000 years, Native American artists adorned rocks, cliff walls, and caves in A

B

the American Southwest with an amazing various of symbolic figures.

$\mathrm{C}$

$\mathrm{D}$

34. Animal researchers have identified many behavioral patterns associated with selection a

A

B

place to live, avoiding predators, and finding food.

$\mathrm{C}$

$\mathrm{D}$

35. Average world temperatures have risen on half a degree Celsius since the mid-nineteenth

A

B C

$\mathrm{D}$

century.

36. The plan connected the Hudson River with Lake Erie by a canal was first proposed in the

A

B

$\mathrm{C}$

late eighteenth century.

$\mathrm{D}$

37. Why certain plants contain alkaloids remains a mystery, although botanists have

A

B

$\mathrm{C}$

formulated a number of theory to explain it.

$\mathrm{D}$

38. Dimness of light will not harm the eyes any more than taking a photograph in dimly light
A
B
C
D

can harm a camera.

39. Contemporary film directors, some of them write the scripts for, act in, and even produce

A

B

their own motion pictures, are thereby assuming ever more control of their art.

$\mathrm{C}$

$\mathrm{D}$

40. Petroleum it is composed of a complex mixture of hydrogen and carbon.
A
$\mathrm{B}$
$\mathrm{C}$
$\mathrm{D}$

\section{Appendix B}

Interview questions

1. In your opinion, what factors make it hard for Thais to communicate in English?

2. If you were tasked with determining English language teaching policy, what would that policy look like?

3. It has often been reported that Thais are poor at English because of an overemphasis on grammar teaching. What do you think about this problem?

4. Based on your personal experience of learning English, what are good things and what should be improved about that experience?

5. Now, you're taking an academic English course, in which you have been taught to do sentence analysis. What do you think about learning English this way? 


\section{Copyrights}

Copyright for this article is retained by the author(s), with first publication rights granted to the journal.

This is an open-access article distributed under the terms and conditions of the Creative Commons Attribution license (http://creativecommons.org/licenses/by/4.0/). 